\title{
Patient navigation: fighting for the rights of breast cancer patients in Brazil
}

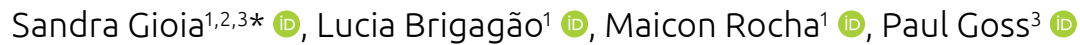

\section{ABSTRACT}

Introduction: The content of this article deals with the experience of the navigation program for patients in a breast cancer diagnosis center of the State Health Department of Rio de Janeiro. The objective was to show how the patient navigation program can allow the proper application of the 60-day Law, being a topic of interest for the planning and evaluation of actions to control this cancer in Brazil. Methodology: The patient navigator accompanied women from the Unified Health System (Sistema Único de Saúde - SUS) with a diagnosis of breast cancer to start treatment at a specialized center within 60 days. Information on the clinical characteristics of the patients, clinical dates and barriers encountered were collected. Univariate logistic regression was used to assess factors associated with starting treatment within 60 days. Results: From January to July 2020, 301 breast biopsies were performed, 126 (42\%) of breast cancer. The mean age was 54 years (26-88). 75\% of the lesions were diagnosed in advanced stages (IIB to IV). The mean time to start treatment was 39 days (11-108). The main barriers found were: fear (93\%), difficulty in communicating with the medical team (81\%), uncoordinated health care (37\%). Being treated outside the city of Rio de Janeiro (RJ) was the main factor associated with treatment within 60 days (79.5\% vs. 20.5\%, $\mathrm{p}<0.001)$. Conclusion: The integration of the patient browser into work processes contributed to compliance with the 60 -day Law in $86 \%$ of cases. In the context of a complex and fragmented healthcare system for a population in a situation of socioeconomic vulnerability, the patient navigation program proves to be a tool to increase the rate of law enforcement in Brazil.

KEYWORDS: breast neoplasms; patient navigation; barriers to access of health services; patient rights.

\section{INTRODUCTION}

Although there is a trajectory of actions for the prevention and control of breast cancer (BC) in Brazil, the scenario of its high incidence, diagnosis at an advanced stage, and high mortality continues to be constant due to barriers regarding access to health care ${ }^{1}$. The estimate for the 2020-2022 triennium is of about 66,280 new cases per year, with an incidence of 61.61 per 100,000 inhabitants ${ }^{2}$. The crude death rate was 15.4 per 100,000 inhabitants, with 16,069 deaths in 2016. There was an increase of $33.6 \%$ in the mortality rate from BC in the period from 1980 to $2016^{2}$.

Approximately $75 \%$ of Brazilians are covered exclusively by the Unified Health System (Sistema Único de Saúde SUS), and although progress toward universal health coverage has been made across the country, large disparities that affect cancer care remain ${ }^{3}$. Women treated in SUS have more advanced disease and worse disease-free and overall survival when compared to women treated in private health care facilities (which can be partially attributed to longer delays and advanced stages in diagnosis) ${ }^{3}$.

The average time for diagnosis is up to 31 days in the private health care system, with $18 \%$ of cases diagnosed in stages III and IV, while in SUS the average is 93 days, and in some cases it can reach up to 180 days, with $40 \%$ of cases diagnosed in these advanced stages. In addition, the average age of $\mathrm{BC}$ diagnosis in Brazil is 53 years, and $30 \%$ to $40 \%$ of women are under 50 years of age. This significant portion of women is outside the Ministry of Health's screening recommendation and has more aggressive and faster growing tumors (HER-2 positive and triple negative subtypes) ${ }^{4.5}$.

Providing quality cancer care to all patients presents numerous challenges, including difficulties in coordination of and access to care. It is "a community-based service delivery intervention designed to promote access to timely diagnosis and treatment of cancer and other chronic diseases, removing barriers to care". Patient navigation has been frequently proposed

${ }^{1}$ Secretaria de Estado de Saúde do Rio de Janeiro - Rio de Janeiro (RJ), Brazil.

${ }^{2}$ Global Cancer Institute - Boston (MA), United States.

${ }^{3}$ Massachusetts General Hospital Cancer Center and Harvard Medical School - Boston (MA), United States.

*Corresponding author: sandra.gioia@gmail.com

Conflict of interests: nothing to declare.

Received on: 03/09/2020. Accepted on: 06/09/2021. 
and implemented to face the challenges of access to cancer care in high-income countries ${ }^{7}$. There are still few studies on patient navigation interventions in cancer treatment in low- and middle-income countries in Asia, South America, and Africa, but all suggest that the provision of navigation services can improve access to cancer care in these countries ${ }^{7}$. All barriers to accessing healthcare resources affect health, overall survival, and mortality rates, which is why a patient navigation program (PNP) is so important. This can ensure that patients receive the help they need on the cancer journey in low- and middle-income countries, particularly in areas where access to health care is fragmented and health systems may be fragile and underfunded ${ }^{8}$.

Recognizing the negative impact of the delay in cancer diagnosis and treatment, in 2012 the Brazilian government issued Law No. 12.732/12 of the Ministry of Health, or the 60-day Law (Lei dos 60 Dias). This law establishes that treatment for any type of cancer for patients in the public health system must start within 60 days of the definitive diagnosis9. In a recent initiative in Rio de Janeiro (RJ), the effectiveness of patient navigation in the public health system from a diagnostic center was proven through an increase in the rate of compliance with the 60-day Law from $10 \%$ to $52 \%{ }^{10}$. This study showed the main factors that contribute to compliance with the Law in Rio de Janeiro ${ }^{11}$ :

- improvement in the structure and processes of diagnostic services (histopathological report with the identification of the molecular subtype, delivery of the report in a medical consultation, direct insertion into the system regulation, performance of staging exams);

- patient navigator acting on the main barriers (fear and fatalistic thoughts and uncoordinated health care);

- treatment outside the capital of Rio de Janeiro.

The content of this article deals with the experience of navigating patients in a BC diagnosis center of the State Health Department of Rio de Janeiro within a womens's hospital, Hospital da Mulher Heloneida Studart (HM), in the city of São João de Meriti (RJ). This diagnostic center serves mainly the Baixada Fluminense (part of the population in Metropolitan Health Region I) ${ }^{12}$. The objective was to offer those interested in the topic, especially managers and health professionals, subsidies to understand, plan and evaluate the actions to control this cancer throughout the continuum of care in which patient navigation intends to allow the proper application of the 60-day Law .

The PNP at HM aims to help women diagnosed with BC start treatment at a specialized center within 60 days. Its target population is women from the SUS with a diagnosis of BC, who need to start treatment at a specialized center. Its main goals are:

- To be successful if at least $70 \%$ of women start treatment within 60 days of histopathological confirmation

- To use the results to inform hospitals and health policy makers about the positive results of patient navigation.

\section{METHODS}

This is an intervention in a diagnostic service in which a social worker was trained to be a patient navigator $(\mathrm{PN})$ with the responsibility of monitoring patients recruited from the day of the breast biopsy at the HM Imaging Center to the start of treatment at the Reference Center determined by the regulation of the State Health Department of Rio de Janeiro. Inclusion criteria were: women with a diagnosis of $\mathrm{BC}$ over 18 years old and attending a public service for consultation regarding a confirmed BC. Exclusion criteria were: no personal documents; patients with private health care insurance; investigation or diagnosis of second primary tumor; patients in the terminal phase of some other disease (prognosis of survival of less than 6 months); uncontrolled comorbidities; history of drug abuse or alcoholism; patients suffering from major psychotic disorders or uncontrolled psychiatric disorders; mentally handicapped patients; incarcerated patients; loss of follow-up.

Contact with the patient took place at least once a week by phone, e-mail, text message or in person. After three consecutive unsuccessful contacts with the patient, navigation was interrupted, this being called loss to follow-up.

Information was collected on the patients' clinical characteristics, clinical dates, barriers encountered, a satisfaction questionnaire, and the Functional Assessment of Cancer Therapy - Breast ${ }^{13}$ questionnaire was applied, which includes a list of statements that other patients with BC judged to be important. Descriptive analysis of population characteristics was performed using measures of central tendency and dispersion (continuous variables) and measures of absolute and relative frequency (categorical variables). To assess factors associated with starting treatment within 60 days, a univariate logistic regression was performed.

\section{RESULTS}

From January to July 2020, 301 breast biopsies were performed, with $126(42 \%)$ positive cases for malignancy. Twenty-three patients were excluded ( 6 died before the biopsy result, 7 were not located, and 10 had private health insurance). Table 1 shows the clinical characteristics of the 103 patients enrolled in the PNP of $\mathrm{HM}$ and of the 85 patients followed up to the start of treatment after additional exclusions (14 due to loss of follow-up, 3 due to investigation of a second primary tumor, and 1 due to uncontrolled comorbidities).

Mean age was 54 years (26-88 years). Forty percent of patients were under 50 years of age, and $84 \%$ reside in Baixada Fluminense. Seventy-five percent of the lesions were diagnosed at an advanced stage (clinical stage IIB to IV). As for the biological profile, $59 \%$ were classified as luminal, $21 \%$ as HER-2 positive, and $20 \%$ as triple negative. Women under 50 years of age were more frequently diagnosed at an advanced stage than women over 50 years $(81 \%$ vs. $77 \%, \mathrm{p}=0.655)$. HER-2 and triple negative 
Table 1. Clinical and treatment characteristics of women with breast cancer $(n=103)$.

\begin{tabular}{|c|c|c|}
\hline Characteristics & $\mathbf{n}$ & $\%$ \\
\hline \multicolumn{3}{|l|}{ Age range, in years } \\
\hline$<50$ & 42 & 40 \\
\hline$\geq 50$ & 61 & 60 \\
\hline \multicolumn{3}{|l|}{ Municipality of residence } \\
\hline Belford Roxo & 12 & 12 \\
\hline Cabo Frio & 05 & 5 \\
\hline Duque de Caxias & 07 & 7 \\
\hline Japeri & 01 & 1 \\
\hline Mesquita & 05 & 5 \\
\hline Nilópolis & 07 & 7 \\
\hline Nova Iguaçu & 25 & 24 \\
\hline Rio de Janeiro & 19 & 18 \\
\hline São João de Meriti & 22 & 21 \\
\hline \multicolumn{3}{|l|}{ Clinical staging at diagnosis } \\
\hline in situ & 00 & 0 \\
\hline I & 03 & 3 \\
\hline IIA & 23 & 22 \\
\hline IIB & 29 & 28 \\
\hline IIIA & 03 & 3 \\
\hline IIIB & 36 & 35 \\
\hline IIIC & 01 & 1 \\
\hline IV & 08 & 8 \\
\hline \multicolumn{3}{|l|}{ Clinical staging at diagnosis } \\
\hline Initial & 26 & 25 \\
\hline Advanced & 77 & 75 \\
\hline \multicolumn{3}{|l|}{ Histological type } \\
\hline Invasive ductal carcinoma & 89 & 86 \\
\hline Invasive lobular carcinoma & 10 & 10 \\
\hline Ductal carcinoma in situ & 03 & 3 \\
\hline Invasive papillary carcinoma & 01 & 1 \\
\hline \multicolumn{3}{|l|}{ Grade } \\
\hline 1 & 06 & 6 \\
\hline 2 & 78 & 76 \\
\hline 3 & 19 & 18 \\
\hline \multicolumn{3}{|l|}{ Biological profile } \\
\hline Luminal A & 25 & 25 \\
\hline Luminal B & 35 & 34 \\
\hline HER-2 positive & 22 & 21 \\
\hline Triple negative & 21 & 20 \\
\hline \multicolumn{3}{|l|}{ Family history for breast cancer } \\
\hline Yes & 29 & 28 \\
\hline No & 74 & 72 \\
\hline \multicolumn{3}{|l|}{ Related death } \\
\hline Yes & 01 & 1 \\
\hline No & 102 & 99 \\
\hline \multicolumn{3}{|l|}{ Additional exclusions } \\
\hline Loss of follow-up & 14 & 14 \\
\hline Second primary tumor & 03 & 3 \\
\hline Uncontrolled comorbidities & 01 & 1 \\
\hline \multicolumn{3}{|l|}{ Type of initial treatment* } \\
\hline Surgery & 16 & 19 \\
\hline Chemotherapy & 64 & 75 \\
\hline Hormone therapy & 5 & 6 \\
\hline \multicolumn{3}{|c|}{ Location of referral center for initial treatment* } \\
\hline Duque de Caxias & 28 & 33 \\
\hline Nova Iguaçu & 26 & 31 \\
\hline Rio de Janeiro & 24 & 28 \\
\hline Cabo Frio & 06 & 7 \\
\hline Espírito Santo & 01 & 1 \\
\hline
\end{tabular}

Initial staging = in situ to IIA, advanced = IIB to IV; Family history for breast cancer = at least one first-degree relative diagnosed with: breast cancer before age 50; bilateral breast cancer or ovarian cancer in any age group; women with a family history of male breast cancer; women with a histopathological diagnosis of proliferative breast lesion with atypia or lobular neoplasm in situ; women with a personal history of breast cancer; *after additional exclusions $n=85$. subtypes were also more frequent in young women $(22 \%$ and $32 \%$ vs. $21 \%$ and $17 \%, \mathrm{p}=0.197)$. Twenty-eight percent of patients had a family history of $\mathrm{BC}$. In the 9-month follow-up, 1 death related to $\mathrm{BC}$ was observed.

The mean times of the main clinical dates were: 59 days (3-179 days) between the mammography report and the biopsy; 20 days (15-30 days) between the biopsy and the histopathological report; 8 days ( $0-18$ days) between the histopathological report and insertion into the regulatory system (SER/RJ); 32 days (0-90 days) between insertion in the regulation and the first consultation with a breast cancer specialist at the referral center. Eightyone percent of patients started treatment with systemic therapy, and $66 \%$ started treatment in Baixada Fluminense (Instituto Oncológico de Nova Iguaçu, Hospital Geral de Nova Iguaçu and Hospital Jardim Amália de Duque de Caxias).

The average time to start treatment was 39 days (11-108 days), with an $86 \%$ compliance rate. Figure 1 shows the number of cases (\%) of BC, according to the time to start treatment.

Table 2 shows the factors associated with treatment within 60 days. Patients who were referred for initial treatment outside the municipality of Rio de Janeiro (Baixada Fluminense, Cabo Frio, and Espírito Santo) were more likely to be treated within 60 days when compared to patients referred for treatment in the municipality of Rio de Janeiro (79.5\% x 20.5\%, p < 0.001$)$.

The main barriers reported by patients are shown in Figure 2. Fear and fatalistic thoughts were reported by $93 \%$ of patients (fear of breast removal, hair loss, chemotherapy side effects, and death and suicidal thoughts). There was a suicide attempt in which the patient reported that, given the possibility of imminent death, she preferred to take her own life as soon as possible. The other barriers identified are attributed to the health system, such as difficulty in communicating with the health team (81\%), uncoordinated health care (37\%), waiting to start treatment (25\%), and the need to redo staging exams (14\%).

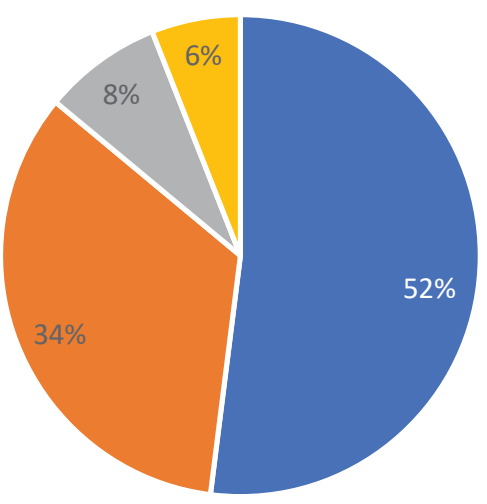

- 30 days | 31 - 60 days $\mid 61$ - 90 days 91 - 189 days

Figure 1. Number of cases (\%) of breast cancer according to time to start treatment. 
Patients' experience was assessed throughout the entire navigation process. With a score of 1 as a very poor experience and a score of 10 as an excellent experience, patients gave scores of 10,9 , and 8 to their overall experience (95\%, $1 \%$, and $4 \%$, respectively). This characterized an excellent performance of the PNP.

Figure 3 shows the patient perception survey with the number (\%) of agreement regarding the PN's relationship and services. Gratitude and nurturing and welcoming reception were the prevalent feelings among the patients, as shown by some statements: "I appreciate the reception with a lot of empathy, clearing up doubts, clarifying what was confusing in my head, offering psychological support”; "This awareness and support work is very important in a place that would only be for the delivery of test results"; "Despite the diagnosis, I feel welcomed and confident in the success of my treatment".

Figure 4 shows the responses to the Functional Assessment of Cancer Therapy-Breast questionnaire. This is a multidimensional questionnaire already well validated and used internationally as an instrument to measure quality of life in patients with BC.

Table 2. Factors associated with treatment within 60 days.

\begin{tabular}{|c|c|c|}
\hline Characteristics & $\begin{array}{c}\text { Time to start } \\
\text { treatment } \\
\leq 60 \text { days }(\%)\end{array}$ & p-value* \\
\hline \multicolumn{3}{|l|}{ Age range (years) } \\
\hline$<50$ & $42(57.5)$ & \multirow{2}{*}{0.626} \\
\hline$\geq 50$ & $31(42.5)$ & \\
\hline \multicolumn{3}{|l|}{ Place of residence } \\
\hline Baixada Fluminense & $61(84)$ & \multirow{3}{*}{0.624} \\
\hline Cabo Frio & $04(5)$ & \\
\hline Rio de Janeiro & $08(11)$ & \\
\hline \multicolumn{3}{|l|}{ Clinical staging at diagnosis } \\
\hline Initial & $14(19)$ & \multirow{2}{*}{0.266} \\
\hline Advanced & $59(81)$ & \\
\hline \multicolumn{3}{|l|}{ Biological profile } \\
\hline Luminal & $42(57.5)$ & \multirow{3}{*}{0.567} \\
\hline HER-2 positive & $15(20.5)$ & \\
\hline Triple negative & $16(22)$ & \\
\hline \multicolumn{3}{|l|}{ Type of initial treatment } \\
\hline Surgery & $11(19)$ & \multirow{2}{*}{0.837} \\
\hline Systemic & $59(81)$ & \\
\hline \multicolumn{3}{|c|}{ Location of referral center for initial treatment } \\
\hline $\begin{array}{l}\text { Outside the municipality } \\
\text { of Rio de Janeiro }\end{array}$ & $58(79.5)$ & \multirow{2}{*}{$<0.001$} \\
\hline $\begin{array}{l}\text { Municipality of } \\
\text { Rio de Janeiro }\end{array}$ & $15(20.5)$ & \\
\hline
\end{tabular}

*Pearson's $\chi^{2}$.

\section{DISCUSSION}

To achieve the goals of the PNP at the HM, changes in work processes were necessary, from scheduling the breast biopsy to the start of treatment. The central pillar was to recognize the importance of understanding patients' experiences regarding patient-centered care ${ }^{14}$. The PNP performance was considered excellent by the patients, and the feeling of gratitude and positive experience prevailed.

Cancer is a disease that significantly affects people's lives, both patients and their families. It entails changes in the routine, from the initial commotion in search of an understanding of the diagnosis, after the first symptoms, through the performing of confirmation tests, referral to a specialist, the various visits to care facilities, the costs involved, the interruption of occupational activities, the concern with subsistence, the waiting time for the start of treatment, fears in the face of uncertainty regarding the response to the proposed treatment and, above all, the stigma associated with the diagnosis ${ }^{15}$.

The help of the navigator was important to reduce the barriers encountered by patients. The solutions found include: explaining the health system, educating patients about the diagnosis and medical procedures, and showing the importance of attending appointments and taking exams (educational barrier); providing more details about the treatment of the disease and referring patients to support groups or individual psychological support (emotional barrier); explaining about the diagnosis and treatment and advising patients about not being alone in this process and communicating the individual needs of each patient with

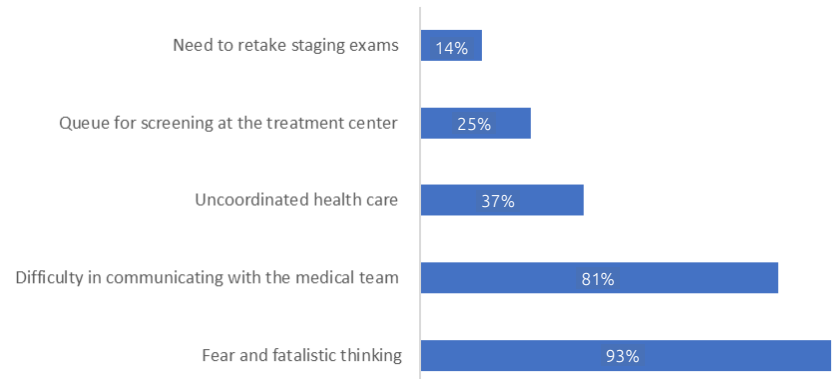

Figure 2. Proportion of barriers reported by patients to start treatment.

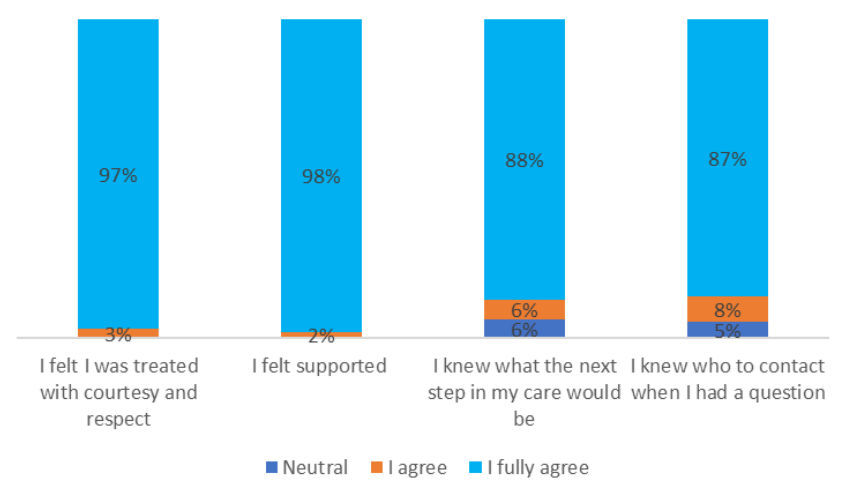

Figure 3. Patient perception survey. 
the medical staff (cultural barrier); coordinating appointments for treatment services and ensuring that the tests needed to start treatment are available to doctors (health system barrier) ${ }^{10}$.

Historically, cancer is perceived as an intractable and devastating disease, with an outcome directly associated with death. This fact is particularly relevant and can be a source of stress and anxiety for patients ${ }^{15}$. In this study, $52 \%$ of patients were stressed with the disease and $72 \%$ were concerned that other family members would one day have the same disease. Hence the importance of focusing and listening to patients, seeking to understand the senses and meanings they attribute to experiencing this illness ${ }^{15}$.

Seventy-six percent of the patients said they felt little, more or less or not sexually attractive, and $58 \%$ managed to feel little, more or less like a woman. It is a process that can be experienced with intense psychological distress in view of the expectations of bodily changes, modification of self-image, impairment of functionality and independence that arise as effects resulting from the indicated treatment, which may involve surgery, chemotherapy, radiotherapy, among other indications. The prevalent issues raised by oncology patients point to the fact that the diagnosis of cancer stimulates emotions and entails a degree of uncertainty and insecurity that include the struggle for dignity and a marked fear for their lifetime ${ }^{16}$.

The main barrier reported by patients was fear and fatalistic thoughts (93\%), as seen in the pioneer study in Rio Imagem in $2018^{10}$ and of Latino populations in the United States ${ }^{17}$. In this sense, the feeling of hope must be encouraged to be part of the patients' trajectory. Despite the fears associated with the disease, it is very important to highlight the current chances of curing and controlling the disease. Maintaining a sense of hope contributes to engaging in possible achievements and positive experiences, despite the changes brought about by theillness. Keeping the routine planning, focusing on achievable activities, preserving the sense of spiritual and/or religious connection, and practicing relaxation activities can contribute to a more hopeful perspective on the scenario that can be disorganizing ${ }^{18}$.

In addition, correct, transparent information, transmitted by respectful and careful communication that must be carried out by the health team, facilitates the understanding of the reality of the disease, helping patients in the search for adequate treatment and favoring a more active posture in the process, whilst the lack of information can lead patients to misunderstand their disease, leading them to seek unconventional therapies, often reinforced by the stigma and consequent prejudice against cancer. It is very important that patients find a safe space for care, and the health team involved must be able to offer an active and empathetic approach to emotional issues ${ }^{18}$.

Seventy-five percent of the patients had advanced disease at diagnosis, $40 \%$ of the patients were considered young, that is, under 50 years of age, and $28 \%$ of the patients had a family history of BC, indicating the importance of expanding patient navigation for primary health care ${ }^{19}$. All patients with family risk reported that they were never instructed about the risks of the disease and how to protect their family members (change in lifestyle, screening for high-risk population, genetic counseling, genetic testing, and prophylactic interventions).

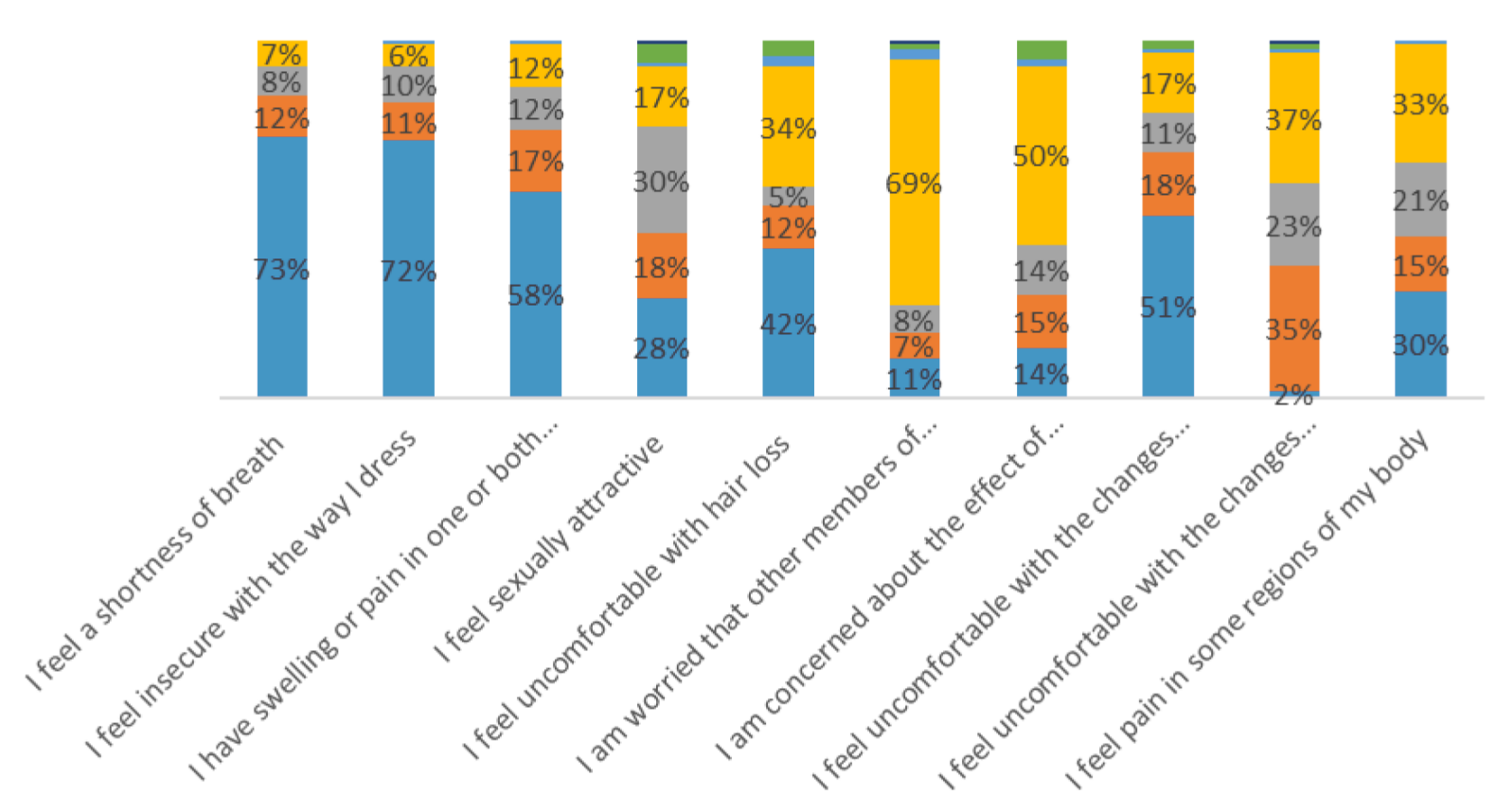

$\square$ Not even a little $\square$ A little $\square$ More or less $\square$ Much $\square$ Very much $\square$ I do not know $\square$ I refuse to answer

Figure 4. Responses to the Functional Assessment of Cancer Therapy-Breast questionnaire. 
Effective actions in the management of care and acting on themain barriers to early detection of $\mathrm{BC}$ can favor adherence to personalized mammographic screening, timely investigation, and access to treatment. ThePNexperiencein the Andaraícommunity,in themunicipality of Rio de Janeiro, showed an increase in the tracking rate from $14 \%$ to $84 \%$, and $100 \%$ of the lesions in 2018 were diagnosed in initial staging ${ }^{19}$.

The compliance rate with the 60-day Law was $86 \%$. Medical records and active search of patients diagnosed in HM in 2019 show that the rate of compliance with the law was 27\% (Sandra Gioia,HM, personal information, 2020). Thus, the introduction of PN was important to increase compliance with the law, reaching the level considered desirable (above 70\%). PN intervention favored the journey of the patients, who, in their majority, needed neoadjuvant chemotherapy and were referred for treatment at the reference centers in Nova Iguaçu (RJ) and Duque de Caxias (RJ) via regulation. And patients with indication for surgical treatment were referred to the General Hospital of Nova Iguaçu. These services do not have waiting lines to start treatment, as seen in services in the city of Rio de Janeiro, which worsened during the COVID-19 pandemic.

Only $20.5 \%$ of patients treated in the city of Rio de Janeiro were able to comply with the law, due to the scarcity of places to start treatment. According to a 2017 report by the State Plan for Oncology Care of the State Health Department of Rio de Janeiro, there is a deficit of 14 units in oncology in Rio de Janeiro, 11 of which are in Metropolitan Region $\mathrm{I}^{12}$. Most states had a worse rate of compliance with the 60-day Law for cases of BC diagnosed in an out-of-hospital environment, with Rio de Janeiro having the worst performance in all of Brazil $(6 \%)^{20}$. Compliance with the 60-day law in oncology is an acquired right, and all Brazilians must strive to ensure that it is properly complied with in accordance with current ethics. Given the inability to comply with the law in Rio de Janeiro, the PNP appears as a promising intervention to reverse this situation. And decision-making intends to be within ethical limits and its dilemmas, especially in the approach to the common good, which is based on the connections of all involved, particularly for those who are considered vulnerable ${ }^{21}$.
Data observed in the real world with the intervention of navigation show the importance of disseminating good results to the medical community and the population. It is expected that the PNP with $\mathrm{BC}$ will become a public health policy in Brazil with exclusive browsers for its area of performance in continuous care ${ }^{1}$. It is also necessary to develop the school and the digital platform for patient navigation to create work organizations based on arrangements of people (health professionals), work processes, and digital technologies to deliver health care with value for the patient, that is, delivering the best outcomes for the patient at a lower cost.

\section{CONCLUSIONS}

The introduction of the PNP for BC was considered successful, with an $86 \%$ compliance rate for the 60 -day Law, but with reservations about the difficulty of complying with the law in the municipality of Rio de Janeiro due to the shortage of human resources and medical supplies.

In the Brazilian context, the PNP can represent an opportunity to properly implement the existing legislation and, as such, it would have a great potential to favor the functioning of the health system in a health care network.

\section{ACKNOWLEDGEMENTS}

Thanks to Instituto Avon and Instituto Gnosis.

\section{AUTHORS' CONTRIBUTIONS}

S.G.: Formal Analysis, Project administration, Validation, Writingoriginal draft, Writing — review \& editing.

L.B.: Supervision.

M.R.: Data curation.

P.G.: Conceptualization, Methodology, Resources, Funding acquisition, Investigation, Writing - review \& editing.

\section{REFERENCES}

1. Gioia SM, Silva SF. Implementation strategies for the guidelines for the early detection of breast cancer in Brazil. Mastology. 2019;29(4):224-35. https://doi.org/10.29289/25945394201920190007

2. Instituto Nacional de Câncer José Alencar Gomes da Silva. Estimativa 2020: incidência de câncer no Brasil [Internet]. Rio de Janeiro: INCA, 2019 [cited on Sept 1, 2020]. Available at: https://www.inca.gov.br/sites/ufu.sti.inca.local/files/media/ document/estimativa-2020-incidencia-de-cancer-no-brasil.pdf

3. Câncer no Brasil: A jornada do paciente no sistema de saúde e seus impactos sociais e financeiros. Interfarma [Internet], 2018 [cited on Sept 1, 2020]. Available at: https://edisciplinas. usp.br/pluginfile.php/6231212/mod_resource/content/3/ cancer-no-brasil-n-a-jornada-do-paciente-no-sistema-desaude-e-seus-impactos-sociais-e-financeiros-interfarma.pdf
4. Rosa DD, Bines J, Werutsky G, Barrios CH, Cronemberger E, Queiroz GS, et al. The impact of sociodemographic factors and health insurance coverage in the diagnosis and clinicopathological characteristics of breast cancer in Brazil: AMAZONA III study (GBECAM 0115). Breast Cancer Res Treat. 2020;183(3):749-57. https://doi.org/10.1007/s10549-020-05831-y

5. Franzoi MA, Rosa D, Zafaroni F, Werutsky G, Simon S, Bines J, et al. Advanced Stage at Diagnosis and Worse Clinicopathologic Features in Young Women with Breast Cancer in Brazil: A Subanalysis of the AMAZONA III Study (GBECAM 0115). J Glob Oncol. 2019;5:1-10. https://doi.org/10.1200/jgo.19.00263

6. Freeman H, Rodriguez R. History and principles of patient navigation. Cancer. 2011;17(150):3539-42. https://dx.doi. org/10.1002\%2Fcncr.26262 
7. Dalton M, Holzman E, Erwin E, Michelen E, Rositch AF, Kumar $\mathrm{S}$, et al. Cancer patient navigation in low-and middle-income countries: A scoping review. Plos One. 2019;14(10):e0223537. https://dx.doi.org/10.1371\%2Fjournal.pone.0223537

8. Calhoun E, Esparza A. Patient Navigation: overcoming barriers care. New York: Springer; 2018.

9. Brasil. Presidência da República. Lei N. 12.732, de 22 de novembro de 2012 [Internet]. Brasil; 2012 [cited on Sept 1,2020]. Available at: http:// www.planalto.gov.br/ccivil_03/_ato2011-2014/2012/lei/112732.htm.

10. Marsillac ML, Gioia S, Silva F, Torres c, Brigadão L, San Miguel S, et al. Improvement of the "Law of 60 Days" by Implementing Patient Navigation within the Breast Cancer Program: Pilot Project in Rio de Janeiro. Acta Sci Cancer Biol. 2020;4(3):42-7. https://dx.doi.org/10.31080/ASCB.2020.04.0203

11. Gioia S, Galdino R, Brigagão L, Valadares A, Secol F, San Miguel S, et al. Prediction of Attendance to the "Law of 60 Days" in Breast Cancer Patients using Machine Learning Classifiers.ActaSci Cancer Biol. 2020;4(3):1628. https://dx.doi.org/10.31080/ASCB.2020.04.0209

12. Rio de Janeiro. Secretaria de Estado de Saúde do Rio de Janeiro. PlanoEstadual de Atenção Oncológica [Internet].Rio deJaneiro: Secretaria de Estado de Saúde do Rio de Janeiro; 2017 [cited on Sept 1, 2020]. Available at: http://www.cib.rj.gov.br/arquivospara-baixar/boletins-cib/2228-planoatencaooncologicafinalcentrosregionaisdiagnostico-052017/file.html.

13. Brady MJ, Cella DF, Mo F, Bonomi AE, Tulsky DS, Lloyd SR, et al. Reliability and validity of the Functional Assessment of Cancer Therapy-Breast quality-of-life instrument. J Clin Oncol. 1997;15(3):974-86. https://doi.org/10.1200/jco.1997.15.3.974

14. Ahmed F, Burt J, Roland M. Measuring patient experience: concepts and methods. Patient. 2014;7(3):235-41. https://doi. org/10.1007/s40271-014-0060-5
15. Oliveira D, Cavalcante L, Carvalho R. Sentimentos de Pacientes em Cuidados Paliativos sobre modificações corporais ocasionadas pelo câncer. Psicol Ciênc Prof. 2019;39:e176879. https://doi.org/10.1590/1982-3703003176879

16. Silva K, Barreto F, Carvalho F, Carvalho PRS. Estratégias de enfrentamento após o diagnóstico de câncer de mama. Rev Bras Prom Saúde. 2020;33:10022. https://doi. org/10.5020/18061230.2020.10022

17. Tejeda S, Darnell JS, Cho YI, Stolley MR, Markossian TW, Calhoun EA. Patient barriers to follow-up care for breast and cervical cancer abnormalities. J Womens Health. 2013;22(6):507-17. https://dx.doi. org/10.1089\%2Fjwh.2012.3590

18. Tamagawa R, Garland S, Vaska M, Carlson LE. Who benefits from psychosocial interventions in oncology: a systematic review of psychological moderators of treatment outcomes. J Behav Med. 2012;35(6):658-73. https://doi.org/10.1007/s10865012-9398-0

19. Gioia S, Brigagão L, Torres C, Lima A, Medeiros M. The implementation of patient navigation to improve mammography coverage and access to breast cancer care in Rio de Janeiro. Mastology. 2019;29(4):186-92. https://doi.org/10 $.29289 / 25945394201920190006$

20. Brasil. Ministério da Saúde. Relatório de Intervalo de Tempo. Integrador RHC [Internet]. Brasil: Ministério da Saúde; 2020 [cited on Sept 1, 2020]. Available at: https://irhc.inca.gov.br/ RHCNet/visualizaTabNetExterno.action

21. Buzaid A, Achatz M, Amorim G, Barrios CH, Carvalho FM, Cavalcante FP, et al. Challenges in the journey of breast cancer patients in Brazil. Braz J Oncol. 2020;16:e-20200021. https:// doi.org/10.5935/2526-8732.20200021 